\title{
Research on Evaluation and Selection of Group Purchase Distribution Mode in Fresh Community ${ }^{1}$
}

\author{
Liu Yang \\ Min Jiang Lihui Li Qian Wu \\ School of Business \\ Hunan University of Technology and Business \\ Changsha, China
}

\begin{abstract}
At present, community group purchase, as an emerging e-commerce model, has begun to attract the attention of major enterprises. The emergence of this model, on the one hand, conforms to the trend of the contemporary era of "group purchase"; on the other hand, it largely meets the consumption needs of different groups and integrates the fragmented market. Distribution is the key to community group purchase, so the choice of the appropriate distribution model has become an urgent problem for community group purchase enterprises. Based on the analysis of the fresh community group purchase distribution mode, this paper uses the Balanced Scorecard to construct the evaluation index system of the fresh community group purchase distribution mode, and uses the related methods of the analytic hierarchy process to evaluate and select the four distribution modes, in order to provide guidance for the development of the fresh community group purchase.
\end{abstract}

Keywords: Fresh produce; Community group purchase; Logistics distribution mode; Evaluation

\section{Introduction}

With the proposal of smart city and the construction of smart community, the concept of community, which is almost forgotten, will appear before people's eyes again. As the entrance of various scenarios such as e-commerce, social network, retail and life services, community group buying has become a hot research topic with the advantages of real offline community and social e-commerce. For fresh community group purchase enterprises, logistics cost is an important factor to determine the success or failure of the enterprise. The key to reduce logistics cost, optimize distribution network, improve distribution efficiency and solve the "last kilometer" problem lies in how to choose an appropriate distribution mode.

This paper takes the distribution of fresh agricultural products in community group purchase mode as the research object, through the analysis on the mainstream community group distribution model, set up evaluation index system of community group distribution mode, using the analytic hierarchy process (ahp) to community group distribution model for quantitative analysis, finally it is concluded that different distribution patterns of final evaluation value and carries on the appraisal

\section{Literature review}

\subsection{Research on fresh agricultural products distribution and fresh e-commerce distribution}

Osvald\&Stirn (2007) proposed a fresh-fashion distribution algorithm based on perish ability as a key factor, which reduced the loss of perishable fresh products by $47 \%$. Tarantilis\&Kiranoudis(2001) study the distribution of fresh milk and build a distribution route for fresh milk based on the minimum time consumption and waste of "freshness". Chen et al. (2008) put forward a non-linear mathematical model of perishable food vehicle routing based on production scheduling, and the non-linear model also has a time window. The model is able to determine the optimal production quantity, the time of production start and the route of the vehicle. In the research of domestic scholars, JupingShao et al.(2015) constructed a VRP model of fresh agricultural products with time windows from the perspective of timeliness. Based on the perishable characteristics of fresh agricultural products, Yaping $\operatorname{Li}(2013)$ constructed a cold chain distribution model from the perspective of cost, which was accurate and feasible.Yuan Gao(2018) improved the distribution mode of novice bird post station by combining SWOT model analysis with ISM analysis.

\footnotetext{
${ }^{1}$ This study was supported by Hunan Provincial Innovation Foundation for Postgraduate(CX2018B764)\& (CX20190897) \&(CX20190887)
} 
Meng Wang(2015) proposed a two-objective model based on the characteristics of fresh products and fresh ecommerce distribution. One goal is to minimize the total distribution cost, and the other is to maximize freshness.Huihun Zhang (2015) \&Baiyi Wang (2016)both took CaiNiao post as an example to analyze the "last kilometer" distribution of fresh food e-commerce.

Minfang Huang et al.(2013) have made pioneering use of artificial intelligence method to generate the intelligent online vehicle path in order to solve the problem of distribution plan scientifically. After analyzing the agricultural product circulation system in developed countries, Zuhui Huang (2003) concluded that the improvement of chain supermarkets and logistics distribution technology is an indispensable part of the development of fresh agricultural products logistics. Based on the research of fresh agricultural products distribution route, Xiaohua Chen et al.(2015)put forward the green distribution model of fresh agricultural products based on green supply chain management.

\subsection{Research on comparative analysis of different distribution modes}

Through the comparative study of domestic and foreign status quo, Dacheng Zhang et al.(2016) proposed multiple distribution modes including joint distribution and intelligent express cabinet, and analyzed them in simple terms. Kun Zhang (2016) put forward the community distribution model and logistics connection model in view of the distribution chaos in Henan province, and made a more detailed analysis, and made countermeasures for the implementation of these distribution models. Danyang Cong (2018) distinguishes different distribution modes by analyzing the proportion of distribution modes determined by enterprises, and then provides a method for enterprises to choose distribution modes through cost analysis. Ermei Liang (2015) studied the development status of community supermarket chains and put forward various community supermarket chain logistics distribution modes, aiming at the logistics distribution efficiency could not keep up with the increasingly rational distribution of supermarket chains. Fang Lin (2004)put forward six kinds of urbanization e-commerce logistics and distribution modes, and analyzed how to choose the distribution mode from the perspectives of large chain snack enterprises, third-party logistics and distribution enterprises and production enterprises in Chengdu.

In summary, there have been some research foundations and achievements in the distribution of fresh agricultural products, fresh e-commerce distribution and comparison of different distribution modes, but as a new field emerging in recent years, fresh community group-buying has rarely been studied.

Therefore, this paper will use the Analytic Hierarchy Process(AHP) to build the fresh community group purchase distribution model evaluation system, the fresh agricultural products community group purchase model evaluation analysis and selection research.

\section{Establishment of the evaluation index system of fresh community group purchase distribution mode}

\subsection{Analysis on distribution model of fresh community group purchase enterprises}

Currently, fresh community group purchase has four distribution modes according to its different operation modes: The first is to distribute the goods to the local community by building warehouses in the local wholesale market (mainstream mode: $\mathrm{B} 2 \mathrm{C}+$ community distribution mode); The second is the distribution from the original place to the warehouse in the city where the products are sold. The customers can pick up the goods in the community or deliver the goods in the community stores through urban logistics (strong enterprise mode: $\mathrm{B} 2 \mathrm{C}+$ physical stores); The third is a proxy distribution (retail mode: B2C + third party distribution mode); The fourth is timely distribution, that is, users in the community We chat group can order half an hour from the warehouse to the user's home (community fresh stores + community mode: $\mathrm{C} 2 \mathrm{~B}+$ home distribution mode).

Fresh is the most critical category in community group buying, which generally accounts for more than $30 \%$.Due to fresh last period is very short, but fresh supply chain is very scattered, even some of the original fresh B2B companies to enter, compared with other enterprise is only in the category segment on the edge, but it is hard to support community group purchase demand for category, on the other hand, through the "reach" rapidly as a selling point of marketing form do not tally with the actual situation. Therefore, the standardization and regional integration capability of fresh supply chain is particularly important.

\subsection{Evaluation index system of group purchase distribution mode of fresh community based on BSC}

This paper refers to the application of Balanced Scorecard in the study of logistics distribution performance evaluation, and introduces Balanced Scorecard into the study of fresh community group purchase distribution model. Select the main indicators of the impact of distribution on the operation of fresh community group purchase enterprises, and construct the evaluation index system of fresh community group purchase distribution mode, which provides the basis for quantitative analysis. 
The evaluation index system of fresh community group purchase distribution model established in this paper is shown in Table 1.

Table 1 evaluation index composition of fresh community group purchase distribution mode based on BSC

\begin{tabular}{|c|c|c|c|}
\hline Target layer & $\begin{array}{l}\text { First-level } \\
\text { index layer }\end{array}$ & $\begin{array}{l}\text { Second-level } \\
\text { index layer }\end{array}$ & Key index layer \\
\hline \multirow{14}{*}{$\begin{array}{l}\text { Composition } \\
\text { of Indicator } \\
\text { System of } \\
\text { Community } \\
\text { Group } \\
\text { Purchase } \\
\text { Distribution } \\
\text { Model }\end{array}$} & \multirow{5}{*}{ Financial Perspective } & Corporate & Profit, Return on Investment, Cost and \\
\hline & & Profitability & Expense Margin \\
\hline & & $\begin{array}{l}\text { Benefit } \quad \text { Growth } \\
\text { Ability }\end{array}$ & Profit Growth Rate, Capital Growth Rate \\
\hline & & $\begin{array}{l}\text { Capital Operating } \\
\text { Capacity }\end{array}$ & $\begin{array}{l}\text { Capital Turnover Rate, Cost Recovery } \\
\text { Period, Inventory Turnover Rate }\end{array}$ \\
\hline & & Solvency & $\begin{array}{l}\text { Current Ratio, Quick Ratio, Capital Debt } \\
\text { Ratio }\end{array}$ \\
\hline & \multirow{3}{*}{ Customer Perspective } & $\begin{array}{l}\text { Products and } \\
\text { Services }\end{array}$ & $\begin{array}{l}\text { Delivery Timeliness, Delivery Error Rate, } \\
\text { Customer Input Rate }\end{array}$ \\
\hline & & & $\begin{array}{l}\text { Customer Appreciation, Cost Advantage, } \\
\text { Customer Lovalty }\end{array}$ \\
\hline & & Market share & Market Share, Brand Effect \\
\hline & \multirow[t]{2}{*}{$\begin{array}{l}\text { Internal Operations } \\
\text { Perspective }\end{array}$} & $\begin{array}{l}\text { Operational } \\
\text { Process }\end{array}$ & $\begin{array}{l}\text { New Product Research and Development } \\
\text { Ability ,Service Innovation Ability } \\
\text { Punctual delivery rate, wastage rate, } \\
\text { average allocation time }\end{array}$ \\
\hline & & $\begin{array}{l}\text { Service } \\
\text { Technology }\end{array}$ & $\begin{array}{l}\text { Customer Response Time, Business } \\
\text { Proficiency }\end{array}$ \\
\hline & \multirow{4}{*}{$\begin{array}{l}\text { Learning } \\
\text { Development } \\
\text { Perspective }\end{array}$} & Employee ability & $\begin{array}{l}\text { Job Satisfaction, Loyalty ,Employee } \\
\text { Learning Ability }\end{array}$ \\
\hline & & $\begin{array}{l}\text { Information } \\
\text { System } \\
\text { Construction }\end{array}$ & $\begin{array}{l}\text { Information Processing Speed, Hardware } \\
\text { Advancement }\end{array}$ \\
\hline & & & Innovation Consciousness, Management \\
\hline & & Corporate Culture & $\begin{array}{l}\text { Hierarchy, Team Consciousness, } \\
\text { Collaboration Ability, } \\
\text { Development Space }\end{array}$ \\
\hline
\end{tabular}

\section{(1)Financial Perspective}

In the market economy environment, the company's goal is to make profits. Finance is the first priority, which is the basis of the company's development. There are four secondary indicators set below the financial perspective:

Corporate profitability: The ability of a company to make profits. It includes three key indicators: profit, return on investment and cost and expense margin.

Benefit growth ability: The ability to grow social labor income through the exchange of goods and labor. It includes two key indicators: profit growth rate and capital growth rate.

Capital operating capacity: The ability to realize value increment through skilled and scientific operation of capital itself by applying market rules. It includes three key indicators: Capital turnover rate, cost recovery period, inventory turnover rate.

Solvency: this is the ability of a business to repay its debts with its assets. It includes three key indicators: current ratio, quick ratio and capital debt ratio.

\section{(2)Customer Perspective}

Customers are the most important part of the market, which is closely related to the activities of enterprises. Three secondary indicators are set under the customer's perspective:

Products and Services: tangible products or intangible services that are market-oriented, can be used and consumed by customers and can meet people's specific needs. It includes three key indicators: delivery timeliness, delivery error rate and customer input rate. 
Customer satisfaction: an index obtained by comparing the perceived effect of a product with the customer's expectation of the product. It includes three key indicators: customer appreciation, cost advantage and customer loyalty.

Market share: refers to the proportion of the total sales of products produced by an enterprise in the total sales of similar products in the market. It includes two key indicators: market share and brand effect.

\section{(3)Internal Operations Perspective}

As market participants, enterprises are constantly optimizing internally while exchanging with the outside world. From the perspective of internal operation, there are three secondary indicators:

Innovation ability: Enterprises continue to attack the old things, break through the old surroundings, improve things and create new things to meet their own development needs, and then harvest the results of competitive advantage of enterprises. It includes two key indicators: new product research and development ability and service innovation ability.

Operational process: The process in which an enterprise can act according to the environment and adapt to the environment better by applying, including but not limited to, changes in its original model. It includes three key indicators: punctual delivery rate, wastage rate and average allocation time.

Service technology: refers to the maximum or minimum service capability provided by a hierarchical and uniform enterprise system. It includes two key indicators: customer response time and business proficiency.

\section{(4)Learning and Development Perspective}

From the perspective of future growth of enterprises, this index considers whether the logistics distribution mode has enough development potential for enterprises, that is, whether a certain logistics mode can make enterprises break the shackles in the future and achieve continuous improvement of performance. From the perspective of learning and development, three secondary indicators are set as follows:

Employee ability: including but not limited to the psychological situation of employees and employees' emotional dependence on the enterprise. It includes three key indicators: job satisfaction, loyalty and employee learning ability.

Information system construction: Integrate these information and information systems. and plan according to priorities to build an information system belonging to the enterprise itself. It includes two key indicators: information processing speed and hardware advancement.

Corporate culture: the cultural concept or material form produced by a company under the specific social background and production conditions. It includes five key indicators: innovation consciousness, management hierarchy, team consciousness, collaborative ability and career development space.

\section{Evaluation and selection of Group Purchase and Distribution Mode in Fresh Community}

\subsection{Construct the judgment matrix of the index}

Based on the summary and induction of expert scoring questionnaire, this paper summarizes and calculates the weight judgment matrix of the first-level index system and the second-level index system.

The weight judgment matrix of the first-level index layer $\mathrm{I}$ to the target $\mathrm{H}$ is as follows:

$$
\mathrm{H}=\left[\begin{array}{cccc}
1 & 1 / 3 & 1 / 2 & 1 / 3 \\
3 & 1 & 1 / 2 & 1 / 2 \\
2 & 2 & 1 & 1 / 3 \\
3 & 2 & 3 & 1
\end{array}\right]
$$

The weight judgment matrix of the second-level index layer $\mathrm{J}$ to the first-level index layer I1 is as follows:

$$
\mathrm{I} 1=\left[\begin{array}{cccc}
1 & 1 / 3 & 1 / 4 & 2 \\
3 & 1 & 1 & 2 \\
4 & 1 & 1 & 2 \\
1 / 2 & 1 / 2 & 1 / 2 & 1
\end{array}\right]
$$

The weight judgment matrix of the second-level index layer $\mathrm{J}$ to the first-level index layer $\mathrm{I} 2$ is as follows:

$$
\mathrm{I} 2=\left[\begin{array}{ccc}
1 & 1 / 2 & 1 \\
2 & 1 & 3 \\
1 & 1 / 3 & 1
\end{array}\right]
$$

The weight judgment matrix of the second-level index layer $\mathrm{J}$ to the first-level index layer $\mathrm{I} 3$ is as follows: 


$$
\mathrm{I} 3=\left[\begin{array}{ccc}
1 & 3 & 3 \\
1 / 3 & 1 & 2 \\
1 / 3 & 1 / 2 & 1
\end{array}\right]
$$

The weight judgment matrix of the second-level index layer $\mathrm{J}$ to the first-level index layer $\mathrm{I} 4$ is as follows:

$$
\mathrm{I} 4=\left[\begin{array}{ccc}
1 & 1 / 5 & 1 / 2 \\
5 & 1 & 4 \\
2 & 1 / 4 & 1
\end{array}\right]
$$

\subsection{Computation of weights at different levels and consistency test}

According to the judgment matrix of the first-level index layer I with respect to the target layer $\mathrm{H}$ and the calculation steps of the analytic hierarchy process principle, the eigenvector and the maximum eigenvalue $\left(\lambda_{\max }\right)$ are calculated by the square root method. The calculation results and consistency test are as follows:

The weight vector of I1, I2, I3 and $\mathrm{I} 4$ with respect to $\mathrm{H}$ is:

$$
\mathrm{L}=\left(\begin{array}{llll}
0.11 & 0.20 & 0.24 & 0.45
\end{array}\right)^{T}
$$

$$
\lambda_{\max }=4.2166, C I=\left(\lambda_{\max }-n\right) /(n-1)=0.0722, R I=0.9000, C R=C I / R I=0.0802<0.1
$$

,the consistency test passed.

The weight vector of $\mathrm{J} 1_{1}, \mathrm{~J} 1_{2}, \mathrm{~J} 1_{3}$ and $\mathrm{J} 1_{4}$ with respect to $\mathrm{I} 1$ is:

$\mathrm{M} 1=\left(\begin{array}{llll}0.14 & 0.35 & 0.38 & 0.13\end{array}\right)^{T}$,

$$
\lambda_{\max }=4.1367, C I=\left(\lambda_{\max }-n\right) /(n-1)=0.0456, R I=0.9000, C R=C I / R I=0.0507<0.1
$$

,the consistency test passed.

The weight vector of $\mathrm{J} 2_{1}, \mathrm{~J} 2_{2}$ and $\mathrm{J} 2_{3}$ with respect to $\mathrm{I} 2$ is:

$\mathrm{M} 2=\left(\begin{array}{lll}0.24 & 0.55 & 0.21\end{array}\right)^{T}$,

$$
\lambda_{\max }=3.0182, C I=\left(\lambda_{\max }-n\right) /(n-1)=0.0091, R I=0.5800, C R=C I / R I=0.0157<0.1
$$

, the consistency test passed.

The weight vector of $3_{1}, \mathrm{~J}_{2}$ and $\mathrm{J} 3_{3}$ with respect to $\mathrm{I} 3$ is:

$$
\begin{aligned}
& \mathrm{M} 3=(0.590 .250 .16)^{T}, \\
& \lambda_{\text {max }}=3.0541, C I=\left(\lambda_{\text {max }}-n\right) /(n-1)=0.0270, R I=0.5800, C R=C I / R I=0.0466<0.1
\end{aligned}
$$

,the consistency test passed.

The weight vector of $\mathrm{J}_{1}, \mathrm{~J} 4_{2}$ and $\mathrm{J} 4_{3}$ with respect to I4 is:

$\mathrm{M} 4=\left(\begin{array}{lll}0.12 & 0.68 & 0.20\end{array}\right)^{T}$,

$$
\lambda_{\max }=3.0252, C I=\left(\lambda_{\max }-n\right) /(n-1)=0.0126, R I=0.5800, C R=C I / R I=0.0466<0.1
$$

,the consistency test passed.

The results are shown in table 2: 
Table 2 I-J Summary of Weights

\begin{tabular}{|c|c|c|}
\hline $\mathrm{J} 1_{1}$ Corporate Profitability & 0.14 & \multirow{4}{*}{ Financial Perspective I1 } \\
\hline $\mathrm{J} 1_{2}$ Benefit Growth Ability & 0.35 & \\
\hline $\mathrm{J} 1_{3}$ Capital Operating Capacity & 0.38 & \\
\hline $\mathrm{J} 1_{4}$ Solvency & 0.13 & \\
\hline $\mathrm{J} 2{ }_{1}$ Products and Services & 0.24 & \multirow{3}{*}{ Customer Perspective I2 } \\
\hline $\mathrm{J} 2{ }_{2}$ Customer Satisfaction & 0.55 & \\
\hline $\mathrm{J} 2{ }_{3}$ Market share & 0.21 & \\
\hline $\mathrm{J} 3_{1}$ Innovation Ability & 0.59 & \multirow{3}{*}{ Internal Operations Perspective I3 } \\
\hline $\mathrm{J} 3_{2}$ Operational Process & 0.25 & \\
\hline $\mathrm{J}_{3}$ Service Technology & 0.16 & \\
\hline $\mathrm{J} 4_{1}$ Employee ability & 0.12 & \multirow{3}{*}{ Learning and Development Perspective I4 } \\
\hline $\mathrm{J}_{4}$ Information System Construction & 0.68 & \\
\hline $\mathrm{J} 4{ }_{3}$ Corporate Culture & 0.20 & \\
\hline
\end{tabular}

After collecting experts' scoring questionnaires and making quantitative analysis, the specific weight table of scheme level $\mathrm{K}$ for the second-level index layer $\mathrm{J}$ is shown in Table 3.

Table 3 J-K Summary of Weights

\begin{tabular}{|c|c|c|c|c|}
\hline $\mathrm{J}_{\mathrm{J}} \mathrm{K}$ & $\begin{array}{l}\text { Mainstream } \\
\text { Mode K1 }\end{array}$ & $\begin{array}{l}\text { Strong Enterprise } \\
\text { ModeK2 }\end{array}$ & $\begin{array}{l}\text { Retail } \\
\text { ModeK3 }\end{array}$ & $\begin{array}{l}\text { Community Fresh Stores } \\
+ \text { Community ModeK4 }\end{array}$ \\
\hline $\begin{array}{l}\mathrm{J} 1{ }_{1} \text { Corporate } \\
\text { Profitability }\end{array}$ & 0.20 & 0.51 & 0.08 & 0.21 \\
\hline $\begin{array}{l}\mathrm{J} 1{ }_{2} \text { Benefit Growth } \\
\text { Ability }\end{array}$ & 0.27 & 0.42 & 0.11 & 0.20 \\
\hline $\begin{array}{l}\mathrm{J} 1{ }_{3} \text { Capital Operating } \\
\text { Capacity }\end{array}$ & 0.23 & 0.41 & 0.10 & 0.26 \\
\hline $\mathrm{J} 1_{4}$ Solvency & 0.10 & 0.48 & 0.26 & 0.24 \\
\hline $\begin{array}{l}\mathrm{J} 2{ }_{1} \text { Products } \quad \text { and } \\
\text { Services }\end{array}$ & 0.16 & 0.47 & 0.09 & 0.28 \\
\hline $\begin{array}{l}\mathrm{J} 22_{2} \text { Customer } \\
\text { Satisfaction }\end{array}$ & 0.16 & 0.38 & 0.14 & 0.32 \\
\hline $\mathrm{J} 2{ }_{3}$ Market share & 0.18 & 0.26 & 0.25 & 0.31 \\
\hline $\begin{array}{l}\text { J3 } 3_{1} \text { Innovation } \\
\text { Ability }\end{array}$ & 0.48 & 0.11 & 0.12 & 0.29 \\
\hline $\begin{array}{l}\mathrm{J}_{3} \text { Operational } \\
\text { Process }\end{array}$ & 0.17 & 0.48 & 0.13 & 0.22 \\
\hline $\begin{array}{l}\mathrm{J}_{3} \text { Service } \\
\text { Technology }\end{array}$ & 0.11 & 0.45 & 0.09 & 0.35 \\
\hline $\mathrm{J} 4_{1}$ Employee ability & 0.43 & 0.17 & 0.18 & 0.22 \\
\hline $\begin{array}{l}\mathrm{J} 4_{2} \text { Information } \\
\text { System Construction }\end{array}$ & 0.20 & 0.40 & 0.11 & 0.29 \\
\hline $\mathrm{J} 4{ }_{3}$ Corporate Culture & 0.39 & 0.18 & 0.09 & 0.34 \\
\hline
\end{tabular}

\subsection{Appraisal of community group purchase distribution model by balanced scorecard}


After determining the weights of 18 corresponding judgment matrices, we can calculate the final evaluation values of different distribution modes for each dimension of the balanced scorecard. The results are shown in Table 4.

Table 4 Summary of four distribution modes' evaluation values for different dimensions

\begin{tabular}{|c|c|c|c|c|}
\hline$\overline{\mathbf{K}}$ & I1 & 12 & I3 & I4 \\
\hline K1 & 0.22 & 0.16 & 0.34 & 0.27 \\
\hline $\mathrm{K} 2$ & 0.43 & 0.38 & 0.26 & 0.33 \\
\hline K3 & 0.12 & 0.15 & 0.12 & 0.11 \\
\hline K4 & 0.23 & 0.31 & 0.28 & 0.29 \\
\hline
\end{tabular}

According to the above data, the final evaluation values of $\mathrm{H}$ of the target layer by different distribution modes can be calculated:

$$
\begin{aligned}
& V=(S 1, S 2, S 3, S 4) \times(L 1, L 2, L 3, L 4)^{T} \\
& =\left[\begin{array}{llll}
0.22 & 0.16 & 0.34 & 0.27 \\
0.43 & 0.38 & 0.26 & 0.33 \\
0.12 & 0.15 & 0.12 & 0.11 \\
0.23 & 0.31 & 0.28 & 0.29
\end{array}\right] \times\left[\begin{array}{llll}
0.11 & 0.20 & 0.24 & 0.45
\end{array}\right]^{T} \\
& =\left[\begin{array}{llll}
0.25 & 0.34 & 0.12 & 0.29
\end{array}\right]^{T}
\end{aligned}
$$

\subsection{Evaluation analysis and selection of community group purchase distribution mode}

According to the above calculation and analysis, it is clear that the final weight of the four logistics distribution modes for the target layer is $(0.25,0.34,0.12,0.29)$. We can see the order of the influence of different distribution modes on enterprise operation, which shows that the ranking of each mode is: strong enterprise mode $(0.34)$, community fresh store + community mode $(0.29)$, mainstream mode $(0.25)$, retail mode $(0.12)$.

From the perspective of the weight of first-level I to target $\mathrm{H}(0.11,0.20,0.24,0.45)$, the ranking order is: learning and development perspective (0.45), internal operations perspective $(0.24)$, customer perspective $(0.20)$, and financial perspective (0.11). This is also consistent with the reality. At present, most of the fresh community group purchase enterprises are in the development stage, more is to pursue long-term growth and future development potential.

From the weight of the four distribution modes for I1 at the financial perspective $(0.22,0.43,0.12,0.23)$, the order is: strong enterprise model (0.43), community fresh store + community model $(0.23)$, mainstream model $(0.22)$ and retail model (0.12).

From the weight of four distribution modes on customer perspective I2 $(0.16,0.38,0.15,0.31)$, the order is: strong enterprise mode $(0.38)$, community fresh store + community mode $(0.31)$, mainstream mode $(0.16)$ and retail mode (0.15).

From the weight of four distribution modes on internal operation perspective I3 $(0.34,0.26,0.12,0.28)$, the order is: mainstream mode $(0.34)$, community fresh store + community mode $(0.28)$, mainstream mode $(0.26)$ and retail mode (0.12).

From the perspective of the weights of the four distribution modes on I4 in the dimension of learning and development $(0.27,0.33,0.11,0.29)$, the order is: strong enterprise model $(0.33)$, community fresh store + community model $(0.29)$, mainstream model (0.27) and retail model (0.11).

According to the principle of maximum membership degree, the current distribution model of strong enterprises: B2C + physical stores as the main mode of enterprises need more powerful company operating capacity, which also coincides with the current characteristics and status quo of community group purchase distribution. When enterprises choose the model of strong enterprises, they will gain more obvious advantages at the financial, customer, learning and development perspectives: when enterprises choose the model of community fresh stores + community, the advantages are more average in the four dimensions; when enterprises choose the mainstream model, they will have advantages at the internal operation perspective.

\section{Discussion}

According to the evaluation index system of community group purchase distribution model based on BSC, this paper uses analytic hierarchy process to construct the evaluation system of community group purchase distribution model based on AHP, and draws the following conclusions after evaluating the four models.

\subsection{Conclusions}


For first-level indicators: fresh community group purchase enterprises pay much more attention to learning and development than financial perspective. In the evaluation of different distribution modes, it is the learning and development scores in the first-level indicators, rather than financial indicators, that play a decisive role. This shows that fresh community group purchase enterprises to choose the distribution mode of the most important thing is their own development.

In the weight of the second-level index layer I to the first-level index layer J:

(1) Benefit growth ability and capital operating capacity have a great impact on the financial perspective. This shows that enterprises pay more attention to the growth rate of profits rather than the growth of profits in finance; they pay more attention to the turnover rate of funds rather than the debt rate of capital.

(2) Customer satisfaction accounts for more than half of the proportion at the customer perspective. Customer satisfaction with the distribution mode chosen by enterprises almost determines the score of different distribution modes at the customer perspective. This means that products and services should not seek the so-called perfection most, but should meet the needs of customers, because the best is not necessarily the best.

The most suitable, but the most suitable must be the best.

(3) Innovation ability accounts for $60 \%$ of the weight in the internal operations perspective, which means that enterprises pay close attention to the cultivation of innovation ability in the internal operations perspective.

(4) At the perspective of learning and development, information system construction plays a decisive role. The most obvious counterexample here is the mainstream mode: $\mathrm{B} 2 \mathrm{C}+$ community distribution mode.

Although this mode has the first score in employee ability and corporate culture, it lacks the construction of information system, which makes it acquire at the perspective of learning and development. The score is not high. Therefore, fresh community group buying enterprises must pay more attention to the construction of information system.

For four distribution modes:

(1) The main points of the mainstream model are to develop its innovative ability, to innovate products and services, and to ensure the full coverage of its service radiation area.

(2) The key point of the model of strong enterprise lies in the solid capital as the backing, the effective use of the original physical store system, and the organic combination of online and offline.

(3) The key point of retail model lies in the selection of reliable third party and the management planning of third party.

(4) The key points of the community fresh store + community model are the refinement of the market and the classification of customers, customization and differentiation of products and services.

To sum up, fresh community group purchase enterprises in the development must grasp the focus of each level, and according to the actual situation to adjust their own strategy.

\subsection{Limitations and directions for future research}

In this paper, the distribution model of fresh community group purchase has been studied and basically reached the research goal. However, there are still many deficiencies in this study, which need further consideration and research.

First of all, in order to facilitate the establishment of an evaluation system, this paper summarizes the current domestic mainstream community group purchase enterprise distribution model, and extracts four major models. However, as a matter of fact, the distribution process of each group purchase company in the community is diverse, and not four modes can be included. If the same thing is said, the evaluation result may be somewhat different from the actual situation. In the future research, we should refine the distribution mode of community group purchase, and optimize different models for different modes.

Then, when using the balanced scorecard, the selected indicators are still too broad in scope. In the future, we can study the factors that affect the distribution model more deeply, reduce the scope of the indicators, make the selected indicators more targeted, and make the research results more convincing and authoritative.

Finally, as a new field emerging in recent years, the fresh community group purchase is rarely studied and there are few relevant literatures in this field. However, with the rise of community economy, the development of e-commerce and the arrival of "group purchase 2.0", people are pursuing high-quality and cheap fresh products. In the future, there will be more and more researches on fresh community group purchase to provide guidance for the development of fresh community group purchase. 


\section{References}

Ana Osvald, Lidija Zadnik Stirn. A vehicle routing algorithm for the distribution of fresh vegetables and similar perishable food[J]. Journal of Food Engineering,2007,85(2).

Baiyi Wang. Research on development countermeasures of "the last kilometer" of e-commerce logistics -- a case study of CaiNiao station [J]. Journal of Jilin normal university of engineering technology,2016,32(01):47-49.

C.D Tarantilis,C.T Kiranoudis. A meta-heuristic algorithm for the efficient distribution of perishable foods[J]. Journal of Food Engineering,2001,50(1).

Dacheng Zhang, Yizhen Zhang. Research on community logistics terminal distribution service model innovation [J]. Re search on business economy,2016(01):114-116.

Danyang Cong. Research on the proportion selection of different modes of community distribution [D]. Beijing Jiaotong university, 2018.

Ermei Liang. Analysis on logistics and distribution strategies of community chain supermarkets [J]. Modern trade industry,2015,36(10):57-58.

Fang Lin. Research on logistics distribution model in China [D]. Southwest Jiaotong university,2004.

Huey-Kuo Chen,Che-Fu Hsueh,Mei-Shiang Chang. Production scheduling and vehicle routing with time windows for perishable food products[J]. Computers and Operations Research,2008,36(7).

Huiyun Zhang,Xin Shang. Analysis of "last kilometer" distribution mode of express delivery industry -- a case study of CaiNiao post and FengChao [J]. Logistics technology,2015,34(22):48-51.

Juping Shao,Qian Cao,Minyan Shen, Yan 'an Sun. VRP model and algorithm of time window in fresh agricultural products distribution [J]. Industrial engineering and management,2015,20(01):122-127+134.

Kun Zhang. Research on the logistics distribution model of fresh agricultural products in Henan province under the ecommerce environment [J]. Journal of economic research,2016(21):45-46.

Meng Wang. Research on optimization model and algorithm of fresh product logistics distribution considering freshness [D]. Dalian university of technology,2018.

Minfang Huang,Yuankai Zhang,Xiangpei Hu. Intelligent generation method of B2C distribution scheme for organic vegetables [J]. Journal of systems engineering,2013,28(05):600-607.

Xiaohu Chen,Xueqing Yan. Distribution model of fresh agricultural products based on green supply chain management [J]. Logistics technology,2015,38(05):95-98.

Yaping Li. Research on optimization of logistics distribution path of fresh agricultural products cold chain [J]. Value engineering,2013,32(31):25-27.

Yuan Gao. Research on improvement and improvement of CaiNiao station distribution model [D]. Hebei university of economics and business, 2018 .

Zuhui Huang,Kexiang Wu, Shaosheng Jin. Changes and enlightenment of modern agricultural products circulation system in developed countries [J]. Fujian BBS (economic and social edition),2003(04):32-36. 